\title{
Capacitação de Mulheres com Empreendimentos Econômicos Solidários para uso das redes sociais no âmbito do Marketing Digital
}

\author{
James L. Dias ${ }^{1}$, Rafael S. Oliveira ${ }^{1}$, Maria da L. O. Dias ${ }^{1}$ \\ 1 Instituto de Federal do Piauí (IFPI) \\ Av. Pedro Freitas, 1020, Vermelha - 64.018-000- Teresina - PI - Brasil \\ \{jamesdias0,rafael.infopiaui, darluzoliveira\}@gmail.com
}

\begin{abstract}
The article present results from the implementation of the project "Women Training Ventures Economic Solidarity for use of web social networking within the Digital Marketing". The study was guided in theoretical and practical actions aimed at semi-distance education with the help of Moodle for use of social networks in favor of Digital Marketing in search of better performance in the dissemination of products Enterprises Economic Solidarity. At the end of the project it was perceivable the importance of social networks through Digital Marketing for Solidarity Economy, since the participants in the project experienced in practice through its products this efficient way to make disclosure.
\end{abstract}

Resumo. O presente artigo é resultado da concretização do Projeto "Formação de Mulheres de Empreendimentos Econômicos Solidários para uso das redes sociais web no âmbito do Marketing Digital”. O estudo pautouse em ações teóricas e práticas voltadas ao ensino semipresencial com auxílio do Moodle para utilização das redes sociais a favor do Marketing Digital em busca do melhor desempenho na divulgação dos produtos de Empreendimentos Econômicos Solidários. Ao final do projeto foi percebível a importância das redes sociais através do Marketing Digital para Economia Solidaria, uma vez que as participantes do projeto vivenciaram na prática por meio dos seus produtos esta forma eficaz de realizar divulgação.

\section{Introdução}

Com o advento das Tecnologias da Informação e Comunicação (TIC) e com a crescente utilização da internet surge uma nova forma de fazer marketing, a forma digital, em que possibilita um alcance imensurável de pessoas que podem visualizar o objeto divulgado, sem contar com o benefício da fácil e rápida comunicação virtual, tudo isso com o auxílio das redes sociais, como por exemplo, Facebook, Twitter, WhatsApp, etc.

De acordo com o exposto acima fica evidenciado que o marketing digital possui fatores importantíssimos na divulgação de produtos, principalmente quando se fala em Empreendimentos Econômicos Solidários. Segundo Lechat et al (2007, p. 177) os Empreendimentos Econômicos Solidários (EES) são organizações que possuem um projeto ideológico que se apoiam na "economia solidária como uma proposta socioeconômica, política e cultural que busca o desenvolvimento humano dentro dos princípios democráticos e de respeito ao meio ambiente, a partir de relações sociais de produção autogestionárias, democráticas e solidárias, antagônicas às do sistema 
capitalista". Se tratando do Estado do Piauí há 753 (setecentos e cinquenta e três) EES cadastrados segundo o Cadastro Nacional de Empreendimentos Econômicos Solidários da Secretaria Nacional de Economia Solidária (SENAES) do Ministério do Trabalho e Emprego (MTE).

Diante dos dados do Atlas de Economia Solidária ${ }^{1}$ formado pelos dados do segundo Mapeamento Nacional de Empreendimentos Econômicos Solidários (EES) no Brasil e finalizado em 2013, 80\% do EES do Piaú não tem acesso ao computador e $82 \%$ não tem acesso a internet. Constando-se que a maioria não utiliza o comércio eletrônico como forma de comercialização, isso se deve a fatores culturais e principalmente ao não acesso à internet. Acarretando na falta de divulgação em alta escala dos produtos e consequentemente uma diminuição nas vendas e lucros dos empreendimentos. Sendo que nesse mesmo Atlas afirma que $12 \%$ das mulheres dos EES do Piauí tem como única fonte de renda das atividades econômica no EES e $38 \%$ é a menor renda da família.

Verificando que um dos problemas enfrentados pelos Empreendimentos Econômicos Solidários é a dificuldade de comercialização de seus produtos devido à pouca divulgação [MORAIS; BRANDÃO; ALBUQUERQUE, 2015] e sabendo do poder de divulgação que o marketing digital têm em conjunto com as redes sociais foi desenvolvido um curso que fornecesse habilidades para 40 mulheres que trabalham com ESS no Estado do Piaúí.

O público alvo atendido pelo projeto eram trabalhadoras que desempenhavam atividades distintas durante o dia. Em atendimento a essas especificidades o curso foi ofertado na modalidade semipresencial para que todas pudessem acompanhar e obtivesse êxito nas atividades propostas. Os encontros presenciais foram realizados aos sábados de 08 horas às 12 horas, retomando das 14 horas às 18 horas. Mas sempre com encontros e interações através do Ambiente Virtual de Aprendizagem (AVA) Moodle. Segundo [SALES; LEITE; JOYE, 2012], o Moodle é um sistema de gerenciamento da aprendizagem que oferece ferramentas para que se criem cursos acessados por um navegador web. $\mathrm{O}$ mesmo possibilita a realização de um acompanhamento síncrono e assíncrono com os usuários da plataforma, e interação por meio dos fóruns.

\section{Métodos}

A natureza da pesquisa está baseada em métodos qualitativos e quantitativos, a primeira, segundo Bogdan \& Biklen (2003), envolve a obtenção de dados descritivos, obtidos no contato direto do pesquisador com a situação estudada, enfatiza mais o processo de aprendizagem do que o produto a ser colhido e se preocupa em retratar a perspectiva dos participantes. Tal abordagem se faz necessária uma vez que, durante o projeto o público alvo estava em constante observação ao desempenhar as atividades propostas em sala de aula pelos executores do projeto, tal procedimento possibilita agregar qualidade e melhorias nos conteúdos, também ajudaria na execução de projetos similares, futuramente as aulas seriam adaptadas para novas turmas. No que se refere o segundo método, Diehl (2004) argumenta que o método quantitativo está pautado no uso da quantificação, tanto na coleta quanto no tratamento das informações, utilizandose técnicas estatísticas, objetivando resultados que evitem possíveis distorções de análise e interpretação, possibilitando uma maior margem de segurança. $\mathrm{O}$ método

\footnotetext{
${ }^{1}$ http://sies.ecosol.org.br/atlas
} 
descriminado se faz importante para a pesquisa, pois o mesmo permite mensurar com clareza dos dados obtidos no projeto e ajuda a justificar a qualidade identificada no método qualitativo.

No que se refere a técnica de coleta de dados, optou-se pela aplicação de questionários e a observação do desempenho do público assistido. A primeira técnica é definida por Marconi \& Lakatos (1996, p. 88) como uma "[...] série ordenada de perguntas, respondidas por escrito sem a presença do pesquisador". O mesmo é importante e vantajoso, pois permite alcançar um maior número de pessoas; é mais econômico; a padronização das questões possibilita uma interpretação mais uniforme dos respondentes, o que facilita a compilação e comparação das respostas escolhidas, além de assegurar o anonimato dos aprendentes avaliados, sem qualquer indução ou condução do resultado. O questionário aplicado foi elaborado com perguntas abertas e fechadas. As perguntas abertas possibilitaram respostas mais ricas e originais e as fechadas maior e melhor facilidade na tabulação e análise dos dados.

O Projeto "Formação de Mulheres de Empreendimentos Econômicos Solidários para uso das redes sociais web no âmbito do Marketing Digital" foi fomentado pelo Programa Institucional de Bolsa de Extensão - PIBEX do Instituto Federal do Piauí (IFPI). Foi realizado com 40 alunas empreendedoras nos laboratórios de informática do IFPI campus Teresina Central presencialmente aos sábados de 08 horas às 12 horas, retomando das 14 horas às 18 horas e de forma virtual no decorrer da semana através de fóruns, chats e atividades online na plataforma Moodle. O curso contou com carga horária total de 84 horas distribuídas de acordo com a tabela 1 a seguir:

Tabela 1. Distribuição das atividades/horas do projeto

\begin{tabular}{|c|c|c|}
\hline Unidades & Conteúdos/Atividades & Carga Horária \\
\hline Primeira aula do Projeto & Aula inaugural e explicativa do projeto & 4 horas \\
\hline $\begin{array}{c}\text { Unidade I } \\
\text { Informática Básica }\end{array}$ & $\begin{array}{l}\text { Conceitos básicos de informática, ligar e } \\
\text { desligar o computador, uso do pacote } \\
\text { office, navegação na internet e utilização } \\
\text { do AVA Moodle. }\end{array}$ & 20 horas \\
\hline \multirow{5}{*}{$\begin{array}{c}\text { Unidade II } \\
\text { Empreendimentos } \\
\text { Econômicos Solidários } \\
\text { para uso das redes } \\
\text { sociais no âmbito do } \\
\text { Marketing Digital }\end{array}$} & Uso das TICs. (Tecnologias da & \multirow{5}{*}{$\begin{array}{c}60 \text { horas } \\
\text { (40h presenciais e } \\
\text { 20h à distância) }\end{array}$} \\
\hline & $\begin{array}{c}\text { Informação e Comunicação) e Redes } \\
\text { Sociais. }\end{array}$ & \\
\hline & Marketing nas Redes Sociais & \\
\hline & Segurança nas Redes Sociais & \\
\hline & Economia solidaria & \\
\hline
\end{tabular}

O projeto foi coordenado por 2 servidores do IFPI, que explicaram os conceitos de Economia Solidaria as Alunas. Contou também com o auxílio de 4 monitores (alunos do Curso de Licenciatura em Informática) que contribuíram com a parte tecnológica do curso, tanto no suporte, cadastro e ambientação das alunas no AVA Moodle, quanto no ensino de Informática Básica e Marketing Digital através das redes sociais. A avaliação do curso se deu por meio de observação do desempenho em sala de aula, questionários, frequência nos laboratórios e participação nas atividades online no AVA.

\section{Resultados e Discussão}

Com base na metodologia desenvolvida foi possível perceber as contribuições que o projeto agregou a cada aluna empreendedora, ou melhor, os resultados foram reunidos 
V Congresso Brasileiro de Informática na Educação (CBIE 2016)

Anais dos Workshops do V Congresso Brasileiro de Informática na Educação (CBIE 2016)

por meio da coleta de dados, utilizando questionário aplicado aos participantes do projeto e da observação de cada aluna no laboratório de informática e no AVA.

$\mathrm{O}$ projeto iniciou suas atividades com 40 (quarenta alunas), e finalizou com 36 (trinta e seis) participantes. Os motivos alegados para a desistência das alunas que não puderam concluir o curso foi que as mesmas eram mães, donas de casa, empreendedoras, etc.... resumindo, elas tinham outras atividades pessoais ou laborativas que não as permitiram prosseguir e concluir o referido curso.

Todas as 36 alunas que concluíram o curso, informaram que se sentem capazes para aplicar os conhecimentos e práticas adquiridas durante a capacitação de acordo com o gráfico 1. Vale ressaltar que mesmo com o avanço das tecnologias, $o$ conhecimento inicial sobre Marketing Digital será fundamental para construção e autonomia de novos conhecimentos. Segundo Silva (2003), essa autonomia refere-se ao desenvolvimento de competências específicas como a aprendizagem que ocorre em regime de maior solidão que a do ensino presencial; e, devido à necessidade de utilizar de forma racional os meios de comunicação e ao desenvolvimento de estratégias pessoais de acesso ao conhecimento, ocorre também o desenvolvimento de capacidades de leitura, escrita, fala e escuta.

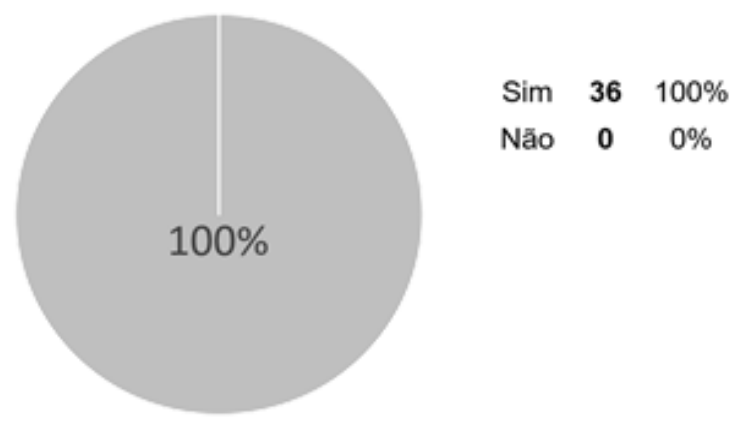

\section{Gráfico 1: Questionário - Você se sente capaz de aplicar os conhecimentos/ práticas adquiridas durante a capacitação?}

Com relação da aplicação dos conhecimentos aprendidos no trabalho foi unanime (gráfico 2), todas afirmaram que sim, os conhecimentos aprendidos são aplicáveis. Resultado muito satisfatório, pois mostrou o sucesso do projeto, uma vez que possibilitou constatar o quanto o curso beneficiou o público atendido.

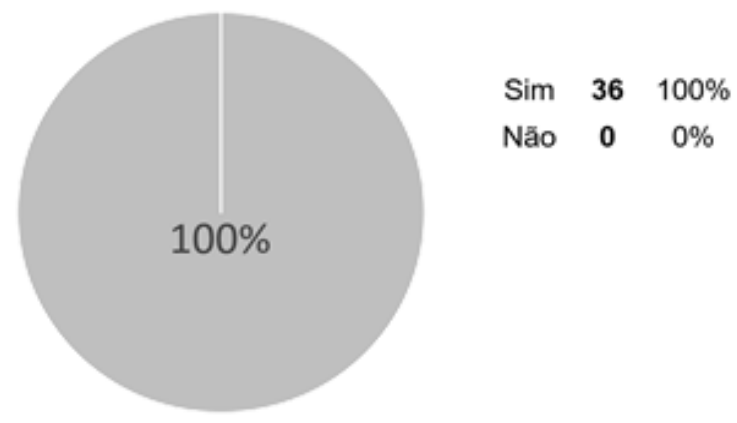

Gráfico 2: Questionário - Os conhecimentos adquiridos no curso são aplicáveis na rotina de trabalho? 
Em outra questão foi perguntado se aconselhariam amigas a fazem o curso e consequentemente participarem do projeto, foi constatado que $100 \%$ das respostas eram sim, que aconselhariam. Foi percebível que o projeto foi motivador para as participantes em buscar de capacitar, onde $100 \%$ responderam que continuariam se capacitando.

\section{Conclusões}

O projeto "Formação de Mulheres de Empreendimentos Econômicos Solidários para uso das redes sociais web no âmbito do Marketing Digital" impulsionou e proporcionou meios para que as alunas empreendedoras fizessem uso das Tecnologias da Informação e Comunicação (TIC), tornando-as capazes para divulgar seus produtos em alta escala através do Marketing Digital e das redes sociais, além de aptas a desenvolver estratégias de empreendedorismos, conforme os contextos de organização da economia solidária.

O projeto desenvolvido pode contribuir como referência para futuros empreendedores que visam uma maior divulgação dos seus produtos por meios digitais. O mesmo poderá também servir de subsídio para projetos semelhantes a serem desenvolvidos em outras cidades do Estado.

\section{Referências}

Bogdan, R. S.; Biklen, S. (2013). Investigação qualitativa em educação: uma introdução à teoria e aos métodos. 12.ed. Porto: Porto, 2003.

Diehl, A. A. (2004). Pesquisa em ciências sociais aplicadas: métodos e técnicas. São Paulo: Prentice Hall, 2004.

Lechat, N. M. P.; Ritter, C.; Lemes, F. R. M.; Schirmer, T. (2007). Gestão de Empreendimentos Econômicos Solidários na Região Noroeste do Rio Grande do Sul. Civitas (Porto Alegre), v. 7, p. 175-194.

Marconi, M. A; Lakatos, E. M. (1996). Técnicas de pesquisa: planejamento e execução de pesquisas, amostragens e técnicas de pesquisas, elaboração e interpretação de dados. 3.ed. São Paulo: Atlas, 1996.

Morais, M.; Brandão, M.; Albuquerque, J. L. (2015). Marketing Digital e Redes Sociais: Um Estudo de Caso na Formação Continuada de Empreendedores Econômicos Solidários no Estado Piauí (Brazil). Revista Eletrônica Argentina-Brasil de Tecnologias da Informação e da Comunicação, v. 1, n. 3, 2015. Disponível em: $<$ http://revistas.setrem.com.br/index.php/reabtic/article/view/90>. Acesso em: 16 de nov. de 2015.

Sales, G. L.; Leite, E. A. M.; Joye, C. R. (2012). O Sistema Acadêmico LV: Avaliação em EaD Online Implementada no Ambiente Virtual Moodle. In: Workshop sobre avaliação e Acompanhamento da Aprendizagem em Ambientes Virtuais. Anais dos Workshops do CBIE, 2012.

Silva, M. (2003). Educação online: teorias, práticas, legislação e formação corporativa. São Paulo: Loyola, 2003. 